\title{
Growth of ZnO nanorods on different substrates using hydrothermal method
}

\author{
Rina Dewi Mayasari a, Aditya Eka Mulyono a, Masmui a, Wawas Swathatafrijiah a, Agustanhakri a, \\ Hanif Yuliani a , R. Ibrahim Purawiardi b, Ratno Nuryadi a, \\ a Center of Technology for Material, Agency for the Assessment and Application of Technology, Puspiptek Building 224, South Tangerang, Banten \\ 15314, Indonesia \\ b Physics Research Center, Indonesian Institutes of Science, Puspiptek Area, South Tangerang, Banten 15314, Indonesia
}

* Corresponding author: ratno.nuryadi@bppt.go.id

\section{Article history}

Received 18 December 2018

Revised 3 March 2019

Accepted 15 August 2019

Published Online 15 April 2020

\section{Graphical abstract}

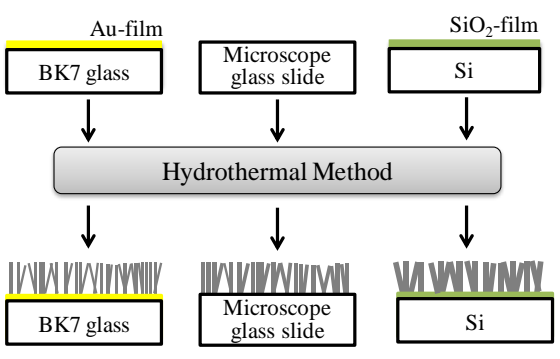

\section{Abstract}

Zinc oxide $(\mathrm{ZnO})$ nanorods have been grown on different substrates, i.e. gold film-coated BK-7 glass (Au-film/BK7), microscope glass slide (MGS), silicon oxide film-coated silicon ( $\mathrm{SiO}_{2}$-film/Si), to investigate the effects of different substrates on its material properties. The growth process was started by dipping substrates in zinc acetate solution to fabricate a seed layer, followed by growing the $\mathrm{ZnO}$ nanorods in zinc nitrate tetrahydrate solution based on hydrothermal method at $95^{\circ} \mathrm{C}$ for 6 hour. In this process, seed layer and $\mathrm{ZnO}$ nanorods were annealed at $350{ }^{\circ} \mathrm{C}$ for 2 hours. The characterization results using X-ray diffraction and field effect scanning electron microscope showed that $\mathrm{ZnO}$ nanorods were successfully grown homogenously and mostly in vertical direction with hexagonal wurtzite structure. The diameter size of $\mathrm{ZnO}$ nanorods was significantly influenced by the type of material substrate. $\mathrm{ZnO}$ nanorods on Au-film/BK-7 glass have the smallest diameter size of $(239 \pm 51) \mathrm{nm}$, while the average diameter size of $\mathrm{ZnO}$ nanorods on MGS is of $(269 \pm 53) \mathrm{nm}$ and $\mathrm{ZnO}$ nanorods on $\mathrm{SiO}_{2}$-film/Si have the largest diameter size of $(354 \pm 80) \mathrm{nm}$. The effect of substrates on different size of $\mathrm{ZnO}$ nanorods may be regarded to the intrinsic thermal conductivity of substrate material. Hence, the synthesis and growth parameters for the different substrates differ from each other and need to be optimized in order to grow $\mathrm{ZnO}$ nanostructures.

Keywords: $\mathrm{ZnO}$ nanorods, hydrothermal, Au-film/BK-7, microscope glass slide, $\mathrm{SiO}_{2}$-film/Si

\section{INTRODUCTION}

Zinc oxide $(\mathrm{ZnO})$ is an inorganic binary compound material in the II-VI material groups which has semiconducting and piezoelectric dual properties (Leprince-Wang, 2015). $\mathrm{ZnO}$ has a wide direct bandgap of $3.37 \mathrm{eV}$ at room temperature, high exciton binding energy of $60 \mathrm{meV}$, transparent to visible light, and can be modified to be a high conductor by doping (Wang, 2004). One dimensional (1D) $\mathrm{ZnO}$ structures have received enormous attention in development for nano-science and technology applications, such as biological and chemical sensors (Mohammed et al., 2017; Bhat et al., 2017), solar cells (Zhu and Zeng, 2017; Ferhati et al., 2018; Liu et al., 2015), electronic and optoelectronic devices ( $\mathrm{Yu}$ et al., 2017), and solar photocatalysts (Capper et al., 2011). 1D ZnO nanostructures including nanorods, nanowires, nanobelts, flower-like, nanotubes, nanoribbons, and nanowishkers have been studied to fulfil the specific requirement of some applications (Wang, 2004; Ong et al., 2018). Among those structures, $\mathrm{ZnO}$ nanorods or nanowires are the most suitable for the building blocks for various devices (Wang, 2010).

Several growth methods of $\mathrm{ZnO}$ nanorods have been reported, such as physical vapor deposition, electrochemical deposition, vapor-phase transport, and pulse laser deposition (Ma et al., 2013). However, those methods need complex processes, sophisticated equipment, high temperature, and high cost (Ong et al., 2018). On the other hand, a hydrothermal is one of the most popular and widely-used $\mathrm{ZnO}$ growth method due to its low temperature process, environmentally friendly, and low cost. In this method, several parameters such as solution $\mathrm{pH}$, temperature, growth time, and calcinations temperature which influence $\mathrm{ZnO}$ nanorods growth morphology were studied (Wang, 2004).

Our previous work reported on the synthesis of $\mathrm{ZnO}$ nanorods on gold film-coated BK-7 glass (Au-film/BK7) for surface plasmon resonance-based gas sensor application (Nuryadi and Mayasari, 2016). However, the $\mathrm{ZnO}$ structures, i.e. individual rod structures and flowerlike structures, are not formed homogeneously on Au surface. The inhomogeneity of $\mathrm{ZnO}$ structures had an effect on insignificant gas response (Yang et al., 2009). Another work was conducted by growing $\mathrm{ZnO}$ microrods on commercial piezoresistive microcantilever which has been fabricated using silicon substrate (Aprilia, et al., 2017). The $\mathrm{ZnO}$ microrods were not well-aligned in flower-like $\mathrm{ZnO}$ structures, hence it needs to be optimized. Type of substrate may also affect the morphology and structure of $\mathrm{ZnO}$ nanorods (Abdulrahman et al., 2016; Singh et al., 2012), but to our knowledge, such studies have been reported only on limited types of samples hence the growth mechanism has not been clearly clarified yet.

In this paper, $\mathrm{ZnO}$ nanorods grown by the hydrothermal method is studied on three different types of substrate, i.e. Au-film/BK-7 glass, 
microscope glass slide (MGS), and silicon oxide film-coated silicon $\left(\mathrm{SiO}_{2}\right.$-film/Si).

\section{EXPERIMENTAL}

Three different types of substrate, i.e. gold thin film $(45 \mathrm{~nm})$ coated on the BK-7 glass (Au-film/BK-7), microscope glass slide (MGS), and silicon oxide thin film coated on high purity silicon wafer $\left(\mathrm{SiO}_{2-}\right.$ film/Si), were used in this experiment. $\mathrm{ZnO}$ nanorods were grown on these substrates using hydrothermal method, which consists of initial seed layer process and growth of $\mathrm{ZnO}$ nanorods, as schematically shown in Fig.1. The details of these processes are explained as follows.

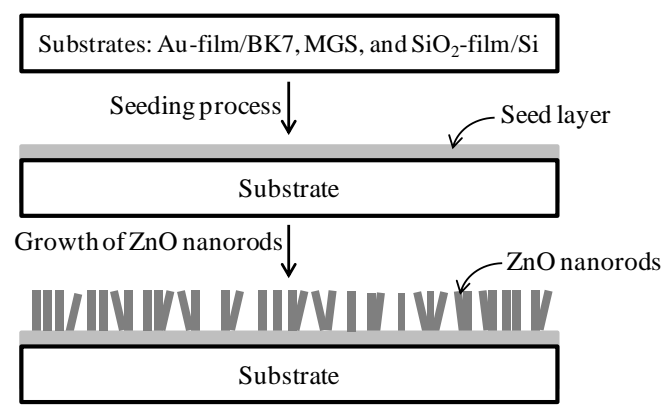

Fig. 1 Scheme of $\mathrm{ZnO}$ nanorods growth process on three substrates, Aufilm/BK7, microscope glass slide, and $\mathrm{SiO}_{2}$-film/Si.

\section{Seeding process}

First, seed layers were deposited on the substrates by dip-coating method (Wahid et al., 2013). The seed solution was prepared by mixing $0.3 \mathrm{M}$ zinc acetate dihydrate $\left[\mathrm{Zn}\left(\mathrm{C}_{2} \mathrm{H}_{3} \mathrm{O}_{2}\right)_{2} . \mathrm{H}_{2} \mathrm{O}\right]$ (Merck, $99.5 \%$ purity) in thylene glycol monomethyl ether solution (Merck, $99.5 \%$ purity) and diethylamin (Merck, $99 \%$ purity) at $60{ }^{\circ} \mathrm{C}$ for 2 hours. After the solution has reached the room temperature, each substrate was dipped in the seed solution for 5 minutes. The dip-coating process was repeated for 3 times and followed by an annealing process. The sample was dried at $100{ }^{\circ} \mathrm{C}$ for 1 hour and then the temperature was increased until $350{ }^{\circ} \mathrm{C}$ for 2 hours with the heat rate of $5^{\circ} \mathrm{C} / \mathrm{min}$. The annealing process helps in improving the structural quality and optical properties of the $\mathrm{ZnO}$ structure (Singh et al., 2012).

\section{ZnO growth process}

After the seeding process, $\mathrm{ZnO}$ nanorods were grown by hydrothermal technique (Yang et al., 2009; Nuryadi and Mayasari, 2016). In this process, $\mathrm{ZnO}$ solution was prepared by dissolving 0.05 $\mathrm{M}$ zinc nitrate hexahydrate $\left[\mathrm{Zn}\left(\mathrm{NO}_{3}\right)_{2} \cdot 6 \mathrm{H}_{2} \mathrm{O}\right]$ (Merck, $98.5 \%$ purity) in $0.05 \mathrm{M}$ hexamethylenetetramine (Merck, 99\% purity) solution. For producing vertical aligned growth of $\mathrm{ZnO}$ nanorods, the substrates were vertically immersed in a sealable bottle containing $\mathrm{ZnO}$ solution and heated at $95{ }^{\circ} \mathrm{C}$ for 6 hours. Afterward, the samples were rinsed with deionized water. Finally, the samples were dried at $100{ }^{\circ} \mathrm{C}$ for 1 hour and the temperature was increased until $350{ }^{\circ} \mathrm{C}$ for 2 hours with the heat rate of $5{ }^{\circ} \mathrm{C} / \mathrm{min}$.

\section{Material characterizations}

$\mathrm{X}$-ray diffraction $(\mathrm{XRD})$ with $\mathrm{CuK}_{\alpha}$ radiation $(\lambda=1.5418 \AA)$ was used to investigate the phase composition and crystalline properties of the samples. The quality of surface morphology and the elemental composition was analyzed by field effect scanning electron microscopy (FESEM) equipped with an energy dispersive X-ray (EDX) spectrometer. In addition, the chemical functional groups of the sample without annealing process were characterized by Fourier transform infra-red (FTIR).

\section{RESULTS AND DISCUSSION}

\section{Crystal structure of $\mathrm{ZnO}$ nanorods}

Fig. 2 shows the XRD patterns of $\mathrm{ZnO}$ nanorods grown on three substrates, which are compared to ICDD No. 01-076-0704 as standard reference of $\mathrm{ZnO}$ phase. From scanning $2 \theta$ axis of the XRD graphs, three peaks which are attributed to $\mathrm{ZnO}$ planes of (100), (002), and (101) are observed. Such peaks indicate that $\mathrm{ZnO}$ nanorods exhibit hexagonal wurtzite structure. The sharp and strong peak of (002) plane reveals that $\mathrm{ZnO}$ nanorods have good crystallinity and vertically aligned with the $c$ axis (Nguyen, 2014). XRD pattern of $\mathrm{ZnO}$ on Aufilm/BK7 substrate has the strongest peak and the highest intensity, while XRD peaks of $\mathrm{ZnO}$ on glass substrate are stronger than $\mathrm{SiO}_{2}-$ film/Si substrate. In addition, ZnO planes of (100) and (101) on glass and $\mathrm{SiO}_{2}$-film/Si substrates are observed in low intensities.

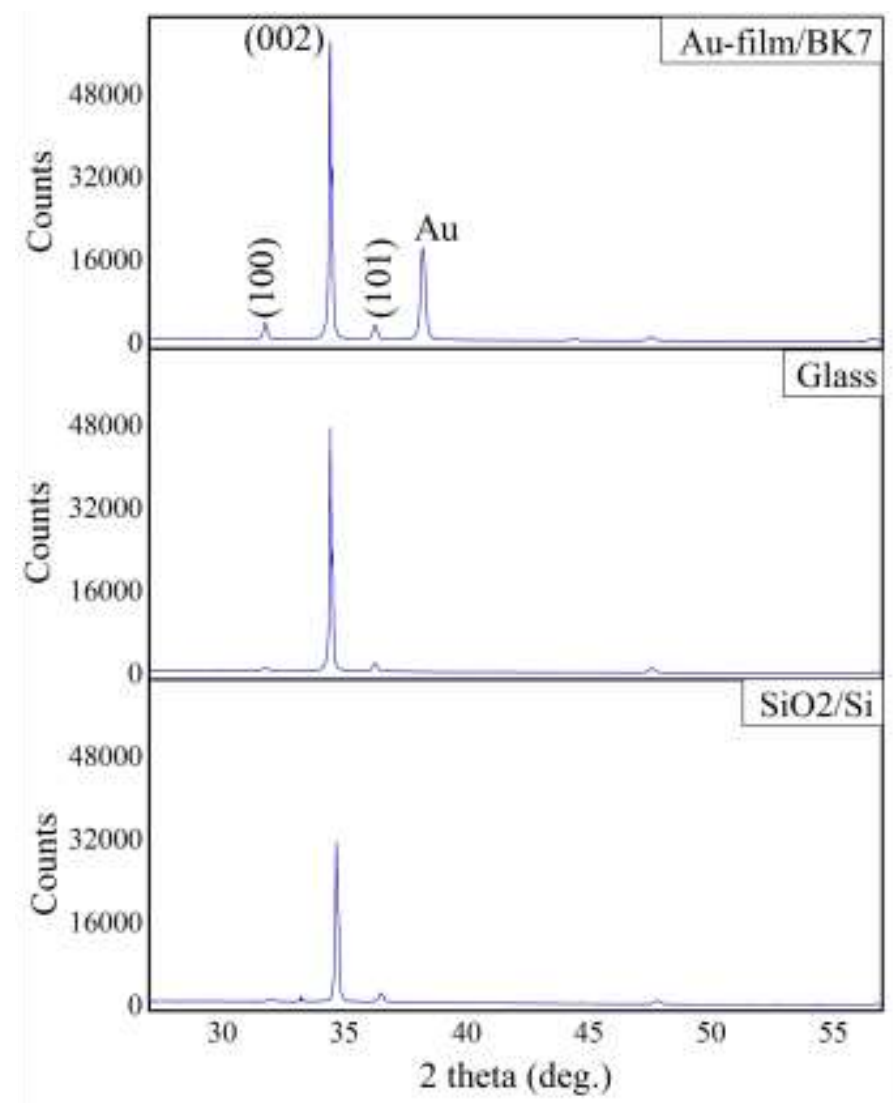

Fig. 2 Diffraction phase of $\mathrm{ZnO}$ nanorods on three substrates: Aufilm/BK-7, Glass, and $\mathrm{SiO}_{2}$-film/Si.

The unit parameter $a$ was estimated to be $3.517 \AA$ for Au-film/BK7 and glass substrates and 3.471 for $\mathrm{SiO}_{2}$ substrate which are close to the bulk $\mathrm{ZnO}$ standard of about $3.253 \AA$ (Yang et al., 2009). In the XRD pattern of $\mathrm{ZnO}$ on $\mathrm{Au}-\mathrm{film} / \mathrm{BK} 7$, the diffraction peak at $2 \theta \approx 36,49^{\circ}$ which is attributed peak "Au" corresponds to the formation of $\mathrm{Au}(100)$ lattice with cubic structure (Nuryadi and Mayasari, 2016).

\section{Element composition and chemical functional groups analysis}

The elemental composition of the samples was analyzed quantitatively using FESEM coupled with EDX technique. EDX results reveal the existence of $\mathrm{Zn}$ and $\mathrm{O}$ elements in the samples without impurities as shown in Fig. 3 (a-c). Composition of $\mathrm{Zn}$ is found to be 84-87\%wt, while $\mathrm{O}$ is $13-16 \%$ wt. The characteristic spectrum confirmed to the characteristic composition of $\mathrm{ZnO}$ as reported previously (Singh et al., 2012). 

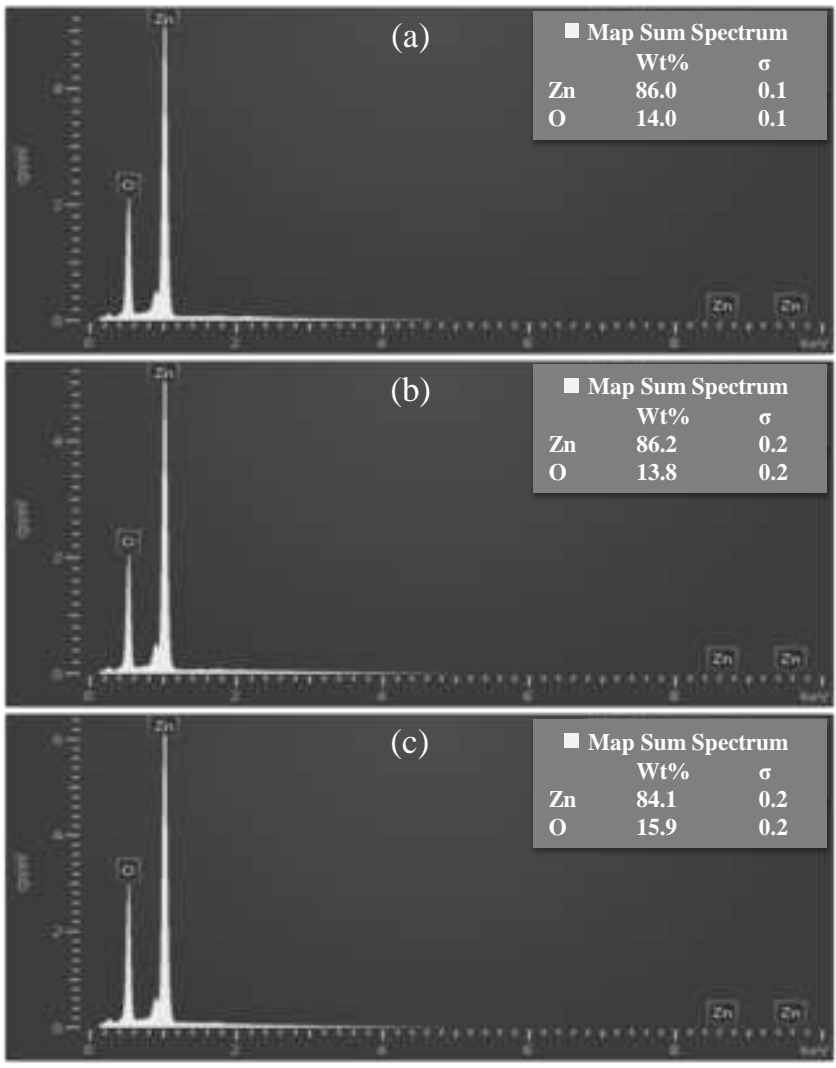

Fig. 3 EDX analysis with element quantity contained in the $\mathrm{ZnO}$ nanorods on the substrates. (a) Au-film/BK-7, (b) MGS, and (c) $\mathrm{SiO}_{2}$-film/Si.

Fig. 4 shows the FTIR spectra of $\mathrm{ZnO}$ nanorods analyzed in the wavenumber region of $400-4000 \mathrm{~cm}^{-1}$. Two strong absorption peaks are observed at 489 and $540 \mathrm{~cm}^{-1}$, corresponding to metal oxide bond $(\mathrm{ZnO})$. Such two bands also confirm the symmetry character of $\mathrm{ZnO}$ in Raman Effect (Xiong et al., 2006). For the Raman-active modes, hexagonal wurtzite $\mathrm{ZnO}$ with $C_{6 V}$ or $6 \mathrm{~mm}$ symmetry have the frequencies of about 437 and $583 \mathrm{~cm}^{-1}$ with the symmetry character $E_{2}$ and $E_{l}$ (longitudinal) modes, respectively (Damen et al., 1966).

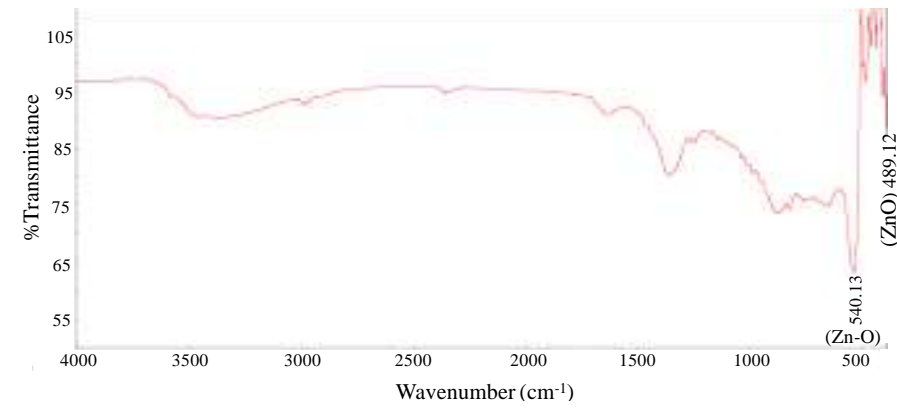

Fig. 4 FTIR spectra of $\mathrm{ZnO}$ nanorods.

\section{Effect of Different Substrates on Morphology of $\mathrm{ZnO}$ Nanorods}

Growth of $\mathrm{ZnO}$ nanorods was carried out on three different substrates with the same main synthesis parameters. Fig. 5 shows FESEM images and $\mathrm{ZnO}$ nanorods diameter size distribution for the three substrates. It can be seen that $\mathrm{ZnO}$ nanorods with hexagonal shape are found for all substrates. It is also known from size distribution graph that the diameters of $\mathrm{ZnO}$ nanorods differ between them. Such structures and different size of $\mathrm{ZnO}$ nanorods were also found by Abdulrahman et al. who grew the $\mathrm{ZnO}$ nanorods on different substrates, i.e. Indium Tin Oxide (ITO) coated glass, polyethylene terephthalate (PET), silicon $(\mathrm{Si})$, and porous $\mathrm{Si}$. Their results demonstrated that the diameter of $\mathrm{ZnO}$ nanorods is closely related to the substrates' nature (Singh et al., 2012).
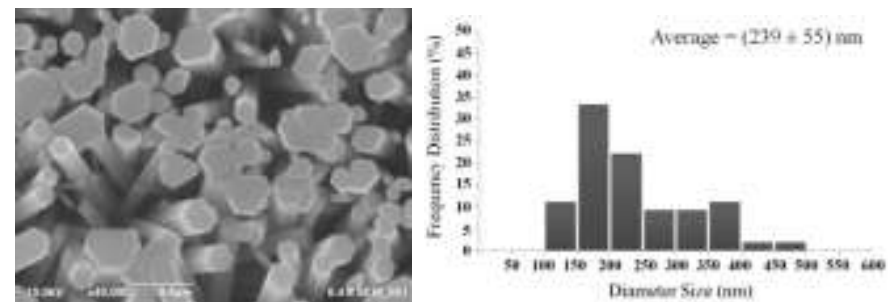

(a)
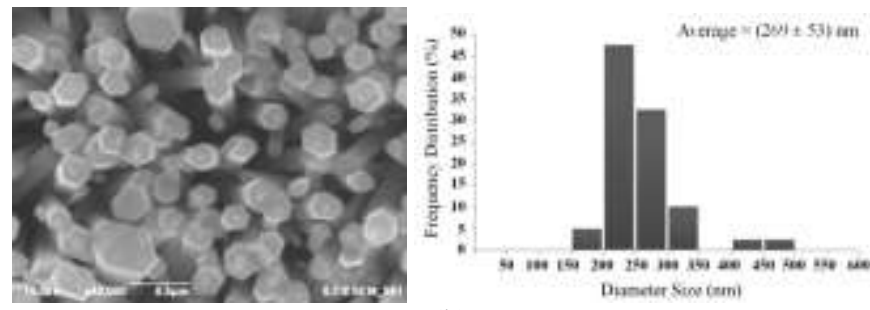

(b)
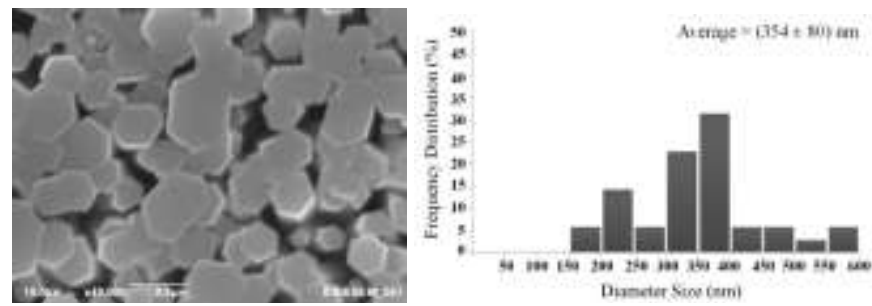

(c)

Fig. 5 FE-SEM image (left) and size distribution of $\mathrm{ZnO}$ nanorods (right). (a) Au-film/BK-7, (b) MGS, and (c) $\mathrm{SiO}_{2}$-film/Si.

$\mathrm{ZnO}$ nanorods on the $\mathrm{Au}$-film/BK-7 have the smallest diameter size of about $(239 \pm 51) \mathrm{nm}$ with the majority of single nanorods. However, the histogram in Fig. 5(a) shows a broad distribution of diameter size which indicates that $\mathrm{ZnO}$ nanorods are not uniform. For $\mathrm{ZnO}$ nanorods on MGS (Fig. 5(b)), the average of $\mathrm{ZnO}$ diameter size is found to be $(269 \pm 53) \mathrm{nm}$ which is larger than $\mathrm{ZnO}$ nanorods on Au-film/BK-7. In the FESEM image, it can be seen that some nanorods have allied and there is new bud on every single nanorods to be broader.

On the other hand, we found that $\mathrm{ZnO}$ nanorods on $\mathrm{SiO}_{2}-\mathrm{film} / \mathrm{Si}$ (Fig. 5(c)) have the biggest diameter size of about $(354 \pm 80) \mathrm{nm}$. This may be caused that most of them have allied. Previously, Yu et al. grew $\mathrm{ZnO}$ nanorods on $\mathrm{Si}$ substrate and reported almost the same result where big diameter size of $\mathrm{ZnO}$ nanorods was obtained ( $\mathrm{Yu}$ et al., 2017b).

The unique thermal properties of material substrates may cause different morphology of $\mathrm{ZnO}$ nanorods. Khusaimi et al. reported that an increase in temperature accelerates the expansion of grain boundaries of $\mathrm{ZnO}$ nanoparticles, interconnection with other granules, and produces bigger grains. Their results are attributed to a tendency for nanoparticles to agglomerate within higher energy at higher temperature (Khusaimi et al., 2012). It can be regarded to thermal conductivity of materials which plays a role to transfer heat in the substrate area (Abu-Eishah, 2001). However, the thermal conductivity of the most pure metals included Au film which has thermal conductivity of $178 \mathrm{~W} \cdot \mathrm{m}^{-1} \cdot \mathrm{K}^{-1}$ tend to decrease following the rise in temperature (Bird, 2002; Kato and Hatta, 2005). Despite of high thermal conductivity, the Au film has thickness of $45 \mathrm{~nm}$ deposited on bulk BK-7 glass which having thermal conductivity of $1.146 \mathrm{~W} \cdot \mathrm{m}^{-1} \cdot \mathrm{K}^{-}$ ${ }^{1}$ (Assael et al., 2008). Therefore, the most influence of transferring heat to the growth process may be performed by the thermal conductivity of glass. It also can be seen to the slight difference of $\mathrm{ZnO}$ diameters between Au film and MGS substrates. Contrary to Au film and glass substrates, $\mathrm{SiO}_{2}$-oxidized $\mathrm{Si}$ wafer owing to high thermal conductivity of $1.241 \mathrm{~W} \cdot \mathrm{m}^{-1} \mathrm{~K}^{-1}$ may transfer heat faster to the area of substrate. As a result, it may accelerate the growth condition and induce the expansion of $\mathrm{ZnO}$ nanorods diameter and length to be bigger and longer. 


\section{CONCLUSION}

In conclusion, the well vertically aligned $\mathrm{ZnO}$ nanorods have been successfully synthesized on three different substrates, i.e. Au-film/BK7, MGS, and $\mathrm{SiO}_{2}-$ film/Si. This study have proven that substrates hold the main role to determine the profiles of $\mathrm{ZnO}$ growth, specifically its structure and surface morphology. The main synthesis parameters cannot be similarized for all types of substrates, hence these aspects need to be optimized and adjusted for each type in order to grow $\mathrm{ZnO}$ nanostructures. An understanding of the substrate effects will guide us to optimize the main parameters of hydrothermal method for gaining the selective growth of $\mathrm{ZnO}$ nanorods.

\section{ACKNOWLEDGEMENT}

The authors would like to thank the Ministry of Science Technology and High Education for supporting our research via Insinas Program 2018.

\section{REFERENCES}

Abdulrahman, A., Ahmed, S., Ahmed, N., Almessiere, M. 2016. Differen substrates effects on the topography and the structure of the $\mathrm{ZnO}$ nanorods grown by chemical bath deposition method. Digest Journal of Nanomaterials and Biostructures, 11, 1007-1016.

Abu-Eishah, S. 2001. Correlations for the thermal conductivity of metals as a function of temperature. International Journal of Thermophysics, 22, 1855 1868.

Aprilia, L., Nuryadi, R., Gustiono, D., Udhiarto, A., Hartanto, D., Yuliarto, B., Hosoda, M., Neo, Y., Mimura, H. 2017. CO Gas-Induced Resonance Frequency Shift of ZnO-Functionalized Microcantilever in Humid Air. Journal of Nanomaterials, 4824607, 1-7.

Assael, M., Antoniadis, K., Wu, J. 2008. New measurements of the thermal conductivity of PMMA, BK7, and Pyrex 7740 up to 450K. International Journal of Thermophysics, 29, 1257-1266.

Bhat, S. S., Qurashi, A., Khanday, F. A. 2017. ZnO nanostructures based biosensors for cancer and infectious disease applications: perspectives, prospects and promises. TrAC Trends in Analytical Chemistry, 86, 1-13.

Bird, R. B. 2002. Transport phenomena. Applied Mechanics Reviews, 55, R1R4.

Capper, P., Kasap, S., Willoughby, A. 2011. Zinc Oxide Materials for Electronic and Optoelectronic Device Applications, John Wiley \& Sons.

Damen, T. C., Porto, S., Tell, B. 1966. Raman effect in zinc oxide. Physical Review, 142, 570 .

Ferhati, H., Djeffal, F., Kacha, K. 2018. Optimizing the optical performance of $\mathrm{ZnO} / \mathrm{Si}$-based solar cell using metallic nanoparticles and interface texturization. Optik-International Journal for Light and Electron Optics, $153,43-49$.
Kato, R., Hatta, I. 2005. Thermal conductivity measurement of thermallyoxidized $\mathrm{SiO}_{2}$ films on a silicon wafer using a thermo-reflectance technique. International Journal of Thermophysics, 26, 179-190.

Khusaimi, Z., Mamat, M., Abdullah, N., Rusop, M. 2012. ZnO nanoparticles on $\mathrm{Si}, \mathrm{Si} / \mathrm{Au}$, and $\mathrm{Si} / \mathrm{Au} / \mathrm{ZnO}$ substrates by mist-atomisation. Journal of Nanomaterials, 2012, 7.

Leprince-Wang, Y. 2015. Piezoelectric ZnO Nanostructure for Energy Harvesting, John Wiley \& Sons.

Liu, X., Wang, G., Ng, A., Liu, F., Ng, Y. H., Leung, Y. H., Djurišić, A. B. Chan, W. K. 2015. Towards low temperature processed ZnO dye-sensitized solar cells. Applied Surface Science, 357, 2169-2175.

Ma, H., Liu, Z., Zeng, D., Zhong, M., Yu, H., Mikmekova, E. 2013. Nanostructured $\mathrm{ZnO}$ films with various morphologies prepared by ultrasonic spray pyrolysis and its growing process. Applied Surface Science, 283, 1006-1011.

Mohammed, A. M., Ibraheem, I. J., Obaid, A., Bououdina, M. 2017. Nanostructured ZnO-based biosensor: DNA immobilization and hybridization. Sensing and bio-Sensing Research, 15, 46-52.

Nguyen, C. P. T., La, P. P. H. L., Trinh, T. T., Le, T. A. H., Bong, S., Jang, K., Ahn, S., Yi, J. 2014. Fabrication of ZnO Nanorods for Gas Sensing Applications Using Hydrothermal Method. Journal of Nanoscience and Nanotechnology, 14, 6261-6265.

Nuryadi, R., Mayasari, R. D. 2016. ZnO/Au-based surface plasmon resonance for CO 2 gas sensing application. Applied Physics A, 122, 33.

Ong, C. B., Ng, L. Y., Mohammad, A. W. 2018. A review of ZnO nanoparticles as solar photocatalysts: Synthesis, mechanisms and applications. Renewable and Sustainable Energy Reviews, 81, 536-551.

Singh, N., Pandey, P., Haque, F. Z. 2012. Effect of heat and time-period on the growth of $\mathrm{ZnO}$ nanorods by sol-gel technique. Optik-International Journal for Light and Electron Optics, 123, 1340-1342.

Wahid, K. A., Lee, W. Y., Lee, H. W., Teh, A. S., Bien, D. C., Azid, I. A. 2013. Effect of seed annealing temperature and growth duration on hydrothermal $\mathrm{ZnO}$ nanorod structures and their electrical characteristics. Applied Surface Science, 283, 629-635.

Wang, Z. L. 2004. Zinc oxide nanostructures: growth, properties and applications. Journal of Physics: Condensed Matter, 16, R829.

Wang, Z. M. 2010. Toward Functional Nanomaterials, Springer New York.

Xiong, G., Pal, U., Serrano, J., Ucer, K., Williams, R. 2006. Photoluminesence and FTIR study of $\mathrm{ZnO}$ nanoparticles: the impurity and defect perspective. physica status solidi c, 3, 3577-3581.

Yang, L.-L., Zhao, Q., Willander, M., Yang, J. 2009. Effective way to control the size of well-aligned $\mathrm{ZnO}$ nanorod arrays with two-step chemical bath deposition. Journal of Crystal Growth, 311, 1046-1050.

Yu, X., Yu, X., Zhang, J., Zhang, D., Chen, L., Long, Y. 2017a. Light-trapping Al-doped $\mathrm{ZnO}$ thin films for organic solar cells. Solar Energy, 153, 96-103.

Yu, Z., Li, H., Qiu, Y., Yang, X., Zhang, W., Xu, N., Sun, J., Wu, J. 2017b. Sizecontrollable growth of $\mathrm{ZnO}$ nanorods on $\mathrm{Si}$ substrate. Superlattices and Microstructures, 101, 469-479.

Zhu, L., Zeng, W. 2017. Room-temperature gas sensing of ZnO-based gas sensor: A review. Sensors and Actuators A: Physical, 267, 242-261. 